\title{
Estimating Premature Mortality Cost of Cancers Attributable to Obesity in Indonesia
}

\author{
Bagus Dwiky Riantoro, Susi Ari Kristina*, Dwi Endarti
}

\begin{abstract}
Obesity is one of the risk factor of non-communicable diseases, one of them is cancer. It may lead to the escalation of mortality. Indonesia is the top 10 country with the highest prevalence of cancer burden due to obesity. The chance of cancer caused by obesity is estimated epidemiologic descriptive and prevalence-based estimation with obesity attributable cancer mortality and Premature Mortality Cost as indicators. Obesity-related cancer mortality is calculated by multiplying Obesity Attributable Fractions (OAFs) rate by cancer death rate, which OAFs rate obtained by calculating obesity prevalence data and relative risk of each disease. Premature Mortality Cost was calculated by multiplying obesity-related cancer mortality, life expectancy, and Indonesian average income. The highest total mortality's rate for obesity-related cancer and overweight-related cancer are colon cancer (929 deaths), ovarian cancer (599 deaths), and pancreatic cancer (190 deaths). The highest value of Premature Mortality Cost are IDR 61,118 million for ovarian cancer, IDR 56,651 million for colon cancer, and IDR 15,472 million for pancreatic cancer. The estimation of cancer burden due to obesity shall be done to help the government determines the health programs and decrease the number of cancer burden due to obesity in Indonesia.
\end{abstract}

Keywords: Obesity- death rate- premature mortality cost- Indonesia

Asian Pac J Cancer Prev, 20 (1), 87-90

\section{Introduction}

The problem of overweight and obesity has become a global problem within the last 10 years (Haslam and James, 2005). According to the World Health Organization (WHO), Body Mass Index (BMI) between $25-29.9 \mathrm{~kg} / \mathrm{m}^{2}$ is defined as overweight and BMI $\geq 30 \mathrm{~kg} / \mathrm{m}^{2}$ as obesity. The prevalence of overweight and obesity in adults increased from 857 million people in 1980 into 2.1 billion in 2013 ( $\mathrm{Ng} \mathrm{M}, 2014)$. An estimated 2 to 7 billion adults are obese or overweight by the year 2030 (Kelly et al., 2008).

Based on national Basic Health Survey in 2013, the prevalence of obesity in adult women ( $>18$ years) in Indonesia has increased 18.1\%, from year 2007 about $14.8 \%$ became $32.9 \%$ (Ministry of Health, 2013). Most of the people are less aware of the dangers of cancer disease risk due to obesity rather than cardiovascular diseases caused by obesity. Obesity considered as factor attributed to numerous cancers such as cancer of the esophagus, colon cancer, liver cancer, gallbladder cancer, pancreatic cancer, and renal cancer (Guh et al., 2009). The death rate of cancer due to obesity show significant results both in men and women. The mortality rate of prostate cancer in men and breast cancer, endometrial cancer, and ovarian cancer in women may escalate as BMI increased
(Forouzanfar et al., 2016). United States study found that overweight and obesity lead to $14 \%$ of cancer deaths due to obesity in men and $20 \%$ of cancer deaths due to obesity in women (Calle et al., 2003).

This study used two indicators to measure the burden of obesity, named obesity attributable cancer mortality and premature mortality cost due to obesity. Based on these data, it can be projected how big the burden of obesity are borne by Indonesia. Thus, the data obtained can be used as a basis for further research in an effort to prevent the occurrence of an increased number of population with obesity.

\section{Materials and Methods}

To conduct the estimation of premature mortality cost of cancers attributable obesity in Indonesia, we carried out four steps. The first step was determining cancer due to obesity by systematic review. The second step was quantifying Obesity Attributable Fractions (OAFs) with relative risks and prevalence of obesity. The third step was calculating the estimation of obesity attributable cancer mortality by multiplying the OAFs with a mortality rate of cancer. The calculation of premature mortality costs have been obtained by multiplying obesity attributable cancers mortality with life expectancy and the average

Department of Pharmaceutics, Faculty of Pharmacy, Universitas Gadjah Mada, Indonesia. *For Correspondence: susiari_k@ugm.ac.id 
income of each gender.

\section{Data Sources}

The prevalence of obesity: prevalence of obesity was obtained from WHO year 2010 in Indonesia (World Health Organization, 2015).

Relative risks: RR cancer associated with obesity are listed in Table 1 (Guh et al., 2009)

Cancer mortality: cancer mortality was obtained from Universal Health Coverage patient database year 2016 and cross checked with mortality data by GLOBOCAN 2012 (International Agency for Research on Cancer, 2012).

Estimated Obesity Attributable Mortality (OAM) and Obesity Attributable Fractions (OAFs) cancer due to obesity

Obesity Attributable Mortality (OAM): OAM was obtained by multiplying the total number of cancer deaths (age group 0-14 years, 15-39 years, 40-44 years, 45-49 years, 50-54 years, 55-59 years, 60-64 years, 65-69 years, 70-74 years and 75 years and over) with the OAFs of each cancer diseases.

Obesity Attributable Fractions (OAFs): this is the proportion of the number of cancer mortality arising from obesity, considering the prevalence of obesity and RR of obesity. OAFs formula is as follow (Flegal et al., 2015):

$$
O A F j=\frac{\sum_{i=1}^{2} P i(R R i j-1)}{\sum_{i=0}^{2} P i(R R i j-1)+1}
$$

Where

OAFij = Body Mass Index (BMI) level (1: BMI = $25.0-29.9 \mathrm{~kg} / \mathrm{m}^{2}$ and $2:$ BMI $>=30 \mathrm{~kg} / \mathrm{m}^{2}$ )

$\mathrm{j}=$ Comorbidity related to obesity $(\mathrm{j}=1-10)$

$\mathrm{Pij}=$ Prevalence of obesity at BMI level 1 or 2 of comorbidity $\mathrm{j}$

RRij $=$ Relative Risk of comorbidity $\mathrm{j}$ associated with BMI level 1 or 2

\section{Premature Mortality Cost}

Estimation of premature mortality cost was conducted by multiplying obesity attributable cancer mortality with life expectancy and the average income. Life expectancy of Indonesian was taken from the WHO data Life Tables year 2012 (World Health Organization, 2012), while the average income of Indonesian population per gender was retrieved from National Statistics Bureau (National Statistics Bureau, 2016). The average income per month was IDR 2.7 million for male and IDR 2.1 million for female (National Statistics Bureau, 2016). All costs were presented in Indonesian Rupiah 2016. For intercountry comparison, costs can be converted into US\$ using the Purchasing Power Parity exchange rate of 1 US $\$=13,204$ IDR.

\section{Results}

The value of RR and OAFs of cancer can be seen in Table 1. Estimation of OAF obtained showed different results between men and women. The value of the OAF of all selected diseases both in the case of overweight or obesity in research was higher in women than men. This might occur because the prevalence of obesity was higher on women in Indonesia.

Table 2 shows that, the largest overweight attributable cancer mortality on male, was colorectal cancer (314 deaths), prostate cancer ( 94 deaths) and pancreatic cancer (51 deaths). In women, the largest overweight attributable cancer mortality was ovarian cancer (411), followed by colorectal cancer (348 deaths) and kidney cancer (73 deaths). The death rate of cancer due to overweight was higher in women (895 deaths) than men (509 deaths).

The biggest cancer mortality due to obesity in men was due to colorectal cancer (111 deaths), followed by pancreatic cancer (42 deaths) and kidney cancer (16 deaths). While in women, the highest cancer mortality due to obesity was ovarian cancer (188 deaths), followed by colorectal cancer (156 deaths) and kidney cancer (45 deaths). The death rate of cancer due to obesity was higher among women (435 deaths) than men (177 deaths).

Table 3 showed the premature mortality cost of cancer caused by obesity in 2016 . The largest premature mortality cost of cancer caused by overweight on men was colorectal cancer (IDR 83,776 million) followed by pancreatic cancer (IDR 13,633 million) and kidney cancer (IDR 10,828 million). While in women, the largest premature mortality cost was ovarian cancer (IDR 155,566 million) followed by colorectal cancer (IDR 78,953 million) and kidney cancer (IDR 17,624 million). In case of obesity, among male, the biggest cost was colorectal cancer (IDR 26,130 million) followed by pancreatic cancer (IDR 9,979

Table 1. Relative Risks and Obesity Attributable Fractions (OAFs) of Cancers

\begin{tabular}{llcccccccc}
\hline ICD-10* & Cancer site & \multicolumn{3}{c}{ Relative risks } & \multicolumn{4}{c}{ OAFs** (\%) } \\
& & \multicolumn{2}{c}{ Overweight } & \multicolumn{2}{c}{ Obesity } & \multicolumn{2}{c}{ Overweight } & \multicolumn{2}{c}{ Obesity } \\
& & Male & Female & Male & Female & Male & Female & Male & Female \\
\hline C18-21 & Colorectal & 1.51 & 1.45 & 1.95 & 1.66 & 9.2 & 10.8 & 2.9 & 4.2 \\
C25 & Pancreatic & 1.28 & 1.24 & 2.29 & 1.6 & 5.3 & 6.1 & 3.8 & 3.8 \\
C56 & Ovarian & - & 1.18 & - & 1.28 & - & 4.6 & - & 1.8 \\
C54 & Endometrial & - & 1.53 & - & 3.22 & - & 12.5 & - & 12.8 \\
C15 & Esophageal & 1.13 & 1.15 & 1.21 & 1.2 & 2.5 & 3.9 & 0.6 & 1.3 \\
C61 & Prostate & 1.14 & - & 1.05 & - & 2.7 & - & 0.2 & - \\
C64-66 & Kidney & 1.4 & 1.82 & 1.82 & 2.64 & 7.3 & 18.1 & 2.5 & 9.8 \\
\hline
\end{tabular}

*ICD-10, International Classification Diseases 10th; **OAFs, Obesity Attributable Fractions 
DOI: 10.31557/APJCP.2019.20.1.87

Premature Mortality Cost of Cancers Attributable to Obesity

Table 2. Overweight and Obesity Attributable Cancer Mortality in Indonesia

\begin{tabular}{llcccccc}
\hline ICD-10* & Cancer site & \multicolumn{2}{c}{ Overweight Attributable Mortality } & \multicolumn{3}{c}{ Obesity Attributable Mortality } \\
& & Male & Female & Total & Male & Female & Total \\
\hline C18-21 & Colorectal & 314 & 348 & 662 & 111 & 156 & 267 \\
C25 & Pancreatic & 51 & 55 & 107 & 42 & 40 & 83 \\
C56 & Ovarian & 0 & 411 & 411 & 0 & 188 & 188 \\
C54 & Endometrial & 0 & 2 & 2 & 0 & 2 & 2 \\
C15 & Esophageal & 7 & 5 & 12 & 2 & 2 & 4 \\
C61 & Prostate & 94 & 0 & 94 & 6 & 0 & 6 \\
C64-66 & Kidney & 42 & 73 & 115 & $16 \mathrm{w}$ & 45 & 62 \\
Total & & 509 & 895 & 1404 & 177 & 435 & 612 \\
\hline
\end{tabular}

*ICD-10, International Classification Diseases $10^{\text {th }}$

Table 3. Premature Mortality Cost of Cancer Attributable Overweight and Obesity in Indonesia

\begin{tabular}{llcccccc}
\hline ICD-10* & Cancer site & \multicolumn{2}{c}{ PMC of Cancer Attributable Overweight (million IDR) } & \multicolumn{3}{c}{ PMC** of Cancer Attributable Obesity (million IDR) } \\
& & Male & Female & Total & Male & Female & Total \\
\hline C18-21 & Colorectal & 83,776 & $78,953.00$ & 162,730 & 26,130 & 30,521 & 56,651 \\
C25 & Pancreatic & 13,633 & 9,433 & 23,066 & 9,979 & 5,492 & 15,472 \\
C56 & Ovarian & 0 & 155,566 & 155,566 & 0 & 61,118 & 61,118 \\
C54 & Endometrial & 0 & 0 & 0 & 0 & 0 & 0 \\
C15 & Esophageal & 1,598 & 700 & 2,299 & 0 & 0 & 0 \\
C61 & Prostate & 354 & 0 & 354 & 0 & 0 & 0 \\
C64-66 & Kidney & 10,828 & 17,624 & 28,452 & 2,718 & 9,525 & 12,243 \\
Total & & 110,190 & 262,279 & 372,469 & 38,828 & 106,658 & 145,486 \\
\hline
\end{tabular}

*ICD-10, International Classification Diseases $10^{\text {th }}$

million) and kidney cancer (IDR 2,718 million). Whereas in women, the highest cost for obesity was ovarian cancer (IDR 61,118 million), followed by colorectal cancer (IDR 30,521 million) and kidney cancer (IDR 9,525 million).

\section{A Sensitivity Analysis}

Based on the sensitivity analysis performed, the results showed that every increase of the overweight and obesity prevalence can increase OAFs, the number of the death and premature mortality cost. In the same way,

Table 4. Sensitivity Analysis of Overweight

\begin{tabular}{lcccccc}
\hline Analysis dan Variable & \multicolumn{2}{c}{ OAFs } & \multicolumn{2}{c}{ Overweight attributable mortality } & \multicolumn{2}{c}{ PMC (million IDR) } \\
& Male & Female & Male & Female & Male & Female \\
\hline $\begin{array}{l}\text { Base case } \\
\text { Sensitivity Analysis }\end{array}$ & 0.27 & 0.56 & 133 & 338 & 110,190 & 262,279 \\
Prevalence increased & & & & & & \\
$5 \%$ & 0.28 & 0.58 & 139 & 354 & 115,216 & 274,375 \\
$10 \%$ & 0.29 & 0.6 & 145 & 369 & 120,201 & 286,383 \\
Prevalence decreased & & & & & & \\
$1 \%$ & 0.26 & 0.55 & 132 & 335 & 109,179 & 259,850 \\
\hline
\end{tabular}

Table 5. Sensitivity Analysis of Obesity

\begin{tabular}{lcccccc}
\hline Analysis and Variable & \multicolumn{2}{c}{ OAFs } & \multicolumn{2}{c}{ Obesity Attributable Mortality } & \multicolumn{2}{c}{ PMC (million IDR) } \\
& Male & Female & Male & Female & Male & Female \\
\hline Base case & 0.1 & 0.33 & 47 & 138 & 38,828 & 106,658 \\
Sensitivity Analysis & & & & & & \\
Prevalence increased & & & & & & \\
$5 \%$ & 0.1 & 0.35 & 50 & 145 & 40,706 & 111,806 \\
$10 \%$ & 0.11 & 0.36 & 52 & 153 & 42,579 & 10612 \\
Prevalence decreased & & & & & & 38,451 \\
$1 \%$ & 0.09 & 0.33 & 47 & 137 & & \\
\hline
\end{tabular}


the decrease of the overweight and obesity prevalence in Indonesia can decrease OAFs, death of cancer and premature mortality cost related to obesity.

\section{Discussion}

Our study found that total premature mortality cost of cancer attributable overweight was IDR 372,469 million and total premature mortality cost of cancer attributable obesity was IDR 145,486 million. Based on the results of the calculation, it shows that female burden of cancer attributable obesity was greater than male. Premature mortality cost of cancer due to overweight was 2.56 times greater than premature mortality cost of cancer due to obesity. This was because the prevalence of overweight was greater than the prevalence of obesity.

The estimated number of the OAF on various cancer diseases has already been done in Thailand earlier (Pitayatienanan et al., 2014) including colorectal cancer and endometrial cancer. The percentage of colorectal cancer OAF in Thailand for men was $8 \%$, whereas, in Indonesia, was about $2.90 \%$. If we compared the value of colorectal cancer OAF on men in this study, colorectal cancer OAF in Thailand has a greater value than Indonesia. While in women, the percentage of OAF in Thailand on endometrial cancer $(17 \%)$ and colorectal cancer $(9 \%)$ is also greater than the number of the OAF on women in Indonesia which are $12.8 \%$ for endometrial cancer and $4.2 \%$ for colorectal cancer. These findings mean that obesity in Indonesia contributes less in causing cancer compared to Thailand. This happens because the prevalence of obesity in Thailand is higher than in Indonesia.

Data published over the last 25 years emphasized that obesity was the cause of $20 \%$ of cancer deaths in women and $14 \%$ in men (Bhaskaran et al., 2014). The American Cancer Society reported that overweight and obesity is correlated with the rate of deaths from pancreatic cancer, myeloma, liver, and Hodgkin's lymphoma (American Cancer Society, 2014). A number of epidemiological studies showed that obesity is a factor that contributed to increase the incidence and mortality of cancer of the colon, endometrial, kidney, and breast postmenopausal (Forouzanfar et al., 2016; Hoque et al., 2016; Murillo-Zamora et al., 2016).

Estimated number of premature mortality cost on various diseases has already been done in Thailand earlier by Pitayatienanan et al., (2014). The amount of the colon cancer premature cost in men in Thailand was 203.5 million Baht or IDR 84,269 million, compared to Indonesia was about IDR 26,130 million. If the premature cost of colon cancer in men in the study compared, the cost of colon cancer in Thailand has a greater amount than Indonesia's premature cost. While in women, the amount of cost in Thailand on endometrial cancer disease is 2.8 million Baht or IDR 1,159 million and colorectal cancer is 119 million Baht or IDR 49,277 million. It is also greater when compared to the amount of premature cost in women in Indonesia which was colorectal cancer (IDR 30,521 million).

There are some limitations that should be recognized in this study. First, the relative risk that are used were not specific to Indonesia but derived from a meta-analysis of other countries due to the unavailability of data for Indonesia. Second, an analysis of burden of obesity being performed only limited 7 types of cancer. Third, population income data used in this research was the average wage/ salary for a month of labour/ employee, whereas for the estimation of the premature mortality cost takes the average income a year. The last, cancer mortality data was the result of a proportion of the estimated mortality from GLOBOCAN (2012) and National Universal Health Coverage data by age group and sex.

It can be concluded that the result of obesity attributable cancer mortality can impact badly on health and economy of the Indonesian government and community. It can be recommended to the government to use these evidences as a basic policy in drawing up the strategy of intervention on prevention and control of obesity.

\section{References}

Bhaskaran K, Douglas I, Forbes H, et al (2014). Body-mass index and risk of 22 specific cancers: a population-based cohort study of 5.24 million UK adults. Lancet, 384, 755-65

Calle EE, Rodriguez C, Walker-Thurmond K, et al (2003). Overweight, obesity, and mortality from cancer in prospectively studied cohort of US adults. $N$ Engl $\mathrm{J} \mathrm{Med,}$ 348, 1625-38.

Flegal KM, Panagiotou OA, Graubard BI (2015). Estimating population attributable fractions to quantify the health burden of obesity. Ann Epidemiol, 25, 201-7.

Forouzanfar MH, Afshin A, Alexander LT, et al (2016). Global, regional, and national comparative risk assessment of 79 behavioural, environmental and occupational, and metabolic risks or clusters of risks, 1990-2015. Lancet, 388, 1659-724.

Guh DP, Zhang W, Bansback N, et al (2009). The incidence of co-morbidities related to obesity and overweight: A systematic review and meta-analysis. BioMed Central Public Health, 9, 88.

Haslam DW, James WP (2005). Obesity. Lancet, 366, 1197-209.

Hoque ME, Mannan M, Long KZ, et al (2016). Economic burden of underweight and overweight among adults in the Asia-Pacific region: a systematic review. Trop Med Intl Health, 21, 458-69.

Kelly T, Yang W, Chen CS, et al (2008). Global burden of obesity in 2005 and projections to 2030 . Intl J of Obesity, 32, 1431-37.

Murillo-Zamora E, Raúl García-Ceballos R, Delgado-Enciso I, et al (2016). Regional-level estimation of expected years of life lost attributable to overweight and obesity among Mexican adults. Glob Health Action, 9, 31642.

$\mathrm{Ng} \mathrm{M}$ (2014). Global, regional, and national prevalence of overweight and obesity in children and adults during 1980-2013: A systematic analysis for the Global Burden of Disease Study 2013. Lancet, 384, 766-81.

Pitayatienanan P, Rukmanee B, Jomkwan Y, et al ( 2014). Economic costs of obesity in Thailand: a retrospective costof-illness study. BMC Health Serv Res, 14, 146.

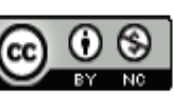

This work is licensed under a Creative Commons AttributionNon Commercial 4.0 International License. 